\title{
Sciendo
}

\section{Cross-Border Capacity-Building for Port Ecosystems in Small and Medium-Sized Baltic Ports}

\author{
Christopher Meyer \\ Hochschule Wismar \\ University of Applied Sciences: \\ Technology, Business and Design \\ Philipp-Müller-Str. 14 \\ Wismar 23966, Germany \\ Tallinn University of Technology \\ Ehitajate tee 5 \\ Tallinn 19086, Estonia \\ Email: christopher.meyer@hs-wismar.de \\ Laima Gerlitz \\ Hochschule Wismar \\ University of Applied Sciences: \\ Technology, Business and Design \\ Philipp-Müller-Str. 14 \\ Wismar 23966, Germany \\ Email: laima.gerlitz@hs-wismar.de \\ Lawrence Henesey \\ Blekinge Institute of Technology \\ Biblioteksgatan 4 \\ Karlshamn SE-37424, Sweden \\ Email: Ihe@bth.se
}

\begin{abstract}
One of the key challenges related to the threat posed by the COVID-19 pandemic is preservation of employment and protecting staff who are working in port operations and struggling to keep ports operating for ship calls. These activities performed by port labour are deemed to be crucial for the EU and European ports, since $75 \%$ of the EU external trade and $30 \%$ of intra-EU transport goods are moved by waterborne transport. As a response to the global lockdown and the vulnerability of global supply chains, the majority of international organisations and maritime ports networks have shortlisted measures necessary to keep the severe
\end{abstract}


effects of the lockdown to a minimum. One of the key measures identified is how to limit physical interaction. As an effect, millions of people and organisations across the globe have had to use and/ or increase their deployment of digital technologies, such as digital documentation, tracing information systems and digital groupworking platforms. Hence, blockchain and data-enabling systems have become to be recognised as a core element maintaining the uninterrupted flow of goods and services at ports.

In pursuing uninterrupted trade and keeping ports open and running, this research paper addresses how the current situation afflicts the small and medium-sized ports located on the Baltic Sea which are argued to be critical actors of the port-centric logistics' ecosystem. Given the topicality of this research and addressing the research gap, the authors suggest a conceptual capacity-building framework for port employees. This suggested framework is based on empirical insights: primary and secondary data collected from the project Connect2SmallPorts, part-financed by the Interreg South Baltic Programme 2014-2020 from the European Regional Development Fund (ERDF). The conceptual framework aims towards a practical training programme dedicated to fill in the missing skills or expand the limited competence of human resources and ports' capacity when adapting or advancing digitalisation in the ports' ecosystems. In particular, specific areas of capacity building are addressed and individual solutions suggested to foster a digital transformation of ports. The conceptual training framework is designed as a training tool indicating opportunities to help ports upgrade their competences with the blockchain technology, and to advance their transportation, environmental and economic performance with improved digitalisation. For this purpose, the conducted research employed mixed methods and applied concepts and approaches based on the field of management. For example, the construct of absorptive capacity, organisational learning, transformation, resource-based view and the concept of dynamic capabilities are included in the ecosystem discourse and are linked with open innovation and service design. The research presented in this article provides both theoretical and practical contributions, in which the affected stakeholders can test and utilise the developed tool as well as transfer it to other regions.

Keywords: blockchain, capacity building, digital transformation, digitalisation, small ports, the Baltic Sea, training 


\section{Introduction}

Seaports in the Baltic Sea Region (BSR) as key regional nodes and gateways of economic and social interactions play a key role in the distribution of goods and services. Thus, millions of people are dependent on the seaports for the provision of critical resources, such as food, energy, raw materials for manufacturing, medical supplies and equipment, etc. As one of the top seas worldwide in maritime traffic (Czermański, 2017), the BSR and its seaports are also facing the consequences of the COVID-19 pandemic. According to a position paper of the Baltic Ports Organisation (BPO, 2020), ports are expecting a noticeable decrease in areas of operations, such as vehicle logistics as a result of the shutdown of manufacturing plants or container and passenger traffic. Especially small and medium-sized ports of the BSR are more exposed in this regard than big ports. One reason for this high exposure is that the small and medium-sized ports are mainly located at the periphery of the key nodes and centres of economic and social interaction, such as the southern coasts of the BSR, for example, in Denmark, Sweden, the northern part of Germany, the Polish coasts as well as the western coastal region of Lithuania. These small and medium-sized ports, being only partly members of the European TEN-T network, make up around 66\% of the total number of ports in the BSR (see European Commission, 2014). They are characterised by smaller freight volumes, missing specialisation, outdated infrastructure, lack of investments and demand for new business models that might accelerate growth and innovation based on diversified and different portfolios (Feng \& Notteboom, 2013).

The small and medium-sized ports of the BSR appear to be under more pressure to quickly respond to and adopt port operations and business models to the ever-changing situation. The focus on digital technologies enabling easier adaptation is regarded as a promising approach, since it provides small and medium-sized ports with improved flexibility due to the upgrade of knowledge and skills as well as enabling better transnational connecting by sharing and integrating services. As a result, such digital technologies as blockchain, blockchain distributed ledger technology (DLT) and data enabling technologies have become crucial for small and mediumsized ports. Small and medium-sized ports are suggested to be more agile and flexible in dealing with the new market challenges (see Feng \& Notteboom, 2013) and also digital transition, but are also limited in their human capital and crucial employee skills, which are most effectively developed and increased within the port environment (see Feng \& Notteboom, 2013). This 
contradiction forms the research problem of a missing conceptual capacitybuilding framework for the digital transformation of the port sector.

In general, seaports increase their interconnection (Edler \& Infante, 2019) as well as digital performance as gateways between different countries and their respective hinterland. Thus, new challenges may arise for the port community which requires capacity-building frameworks beyond port operations, engineering and management, while considering also the skills and knowledge of general business, logistics and, especially, digital transformation (Thai, 2012). With regard to the new roles and developments of seaports as important actors in regional development and innovation strategies (Efimova \& Gapochka, 2020; Philipp et al., 2020), to multimodal nodes to break contact for economic and social welfare (Benassi et al., 2015; Llano et al., 2017) and a multiport gateway for transnational connections (Feng \& Notteboom, 2013), the conceptual framework in this paper is based on a cross-border perspective. Sweeney and Evangelista (2005) already concluded back in 2005 that a cross-border approach is a more efficient method for learning needs analysis, training design and implementation for port communities, but to date there is no record of published research in the particular field nor consideration of these factors for deducing potential cross-border capacity-building frameworks. This clearly postulates the addressed research gap of this research.

Furthermore, Chen et al. (2017) analysed capacity-building activities in small ports suggesting the approach of learning from others for an efficient and successful improvement of the ports' human resources. Therefore, this article provides a theoretical contribution by filling the research gap of the lack of cross-border concepts for the capacity building of port communities in small and medium-sized ports with a focus on the BSR, by posing the research question of how to structure an adoptable cross-border capacitybuilding framework for the digital transformation of small and mediumsized port ecosystems based on their actual skills and needs.

In addition, the article contributes by assisting practical research in the field as a first step to develop a cross-border framework to be transferred and offered to small and medium-sized ports as well as considering individual regional preferences. Thus, the paper serves as a practical conceptualisation of the implementation of capacity building to be directly transferred into a running course programme for increasing the competitiveness of small and medium-sized ports in the BSR and beyond. 
By tackling this research question, the research objective of the current article also contributes to the Blue Growth Strategy for the BSR (European Commission, 2017) and the European Green Deal of the European Commission (COM/2019/640 final) by improving the conditions for the competitiveness of small and medium-sized ports. Hence, the conducted research supports European Blue Economy in line with Regional Innovation Strategies on Smart Specialisation (RIS3), which is also seen as a crucial policy approach for the implementation of the EU Green Deal (Gianelle et al., 2020; Larosse et al., 2020). Besides research and development as well as networking, training is seen as a key enabling procedure to foster and implement the smart specialisation approach (Prause, 2014), underlining the importance of this research article and its impact on the Baltic Sea and European development.

The article is structured as follows: the next chapter provides the theoretical context with a focus on existing concepts and published research for small and medium-sized ports as well as cross-border capacity building frameworks. Following the introduction of the applied research methodology, a demandside analysis is provided by examining the particular digital needs of ports and their human capital. In the fifth chapter, the actual capacity-building framework on cross-border perspective is developed and introduced, followed by a conclusion and discussion of research results.

\section{Theoretical background}

In the field of research and business, there is no unified definition on what a small port actually is (PAC2, 2014). One policy used for classification is that of the TEN-T network, which identifies a port as small if it belongs to the network as a comprehensive port or does not even belong to the network. Feng and Notteboom (2011) developed applicable criteria as an additional approach for defining a small port by means of transport volume, international connectivity, relative cluster position, hinterland capture area as well as the GDP of the port city and hinterland. Another approach to frame small and medium-sized ports is classification according to their specific main functionalities: (i) enhancing blue economy competitiveness; (ii) actors in regionalisation processes and (iii) the key capacity to set up multiport gateway regions (Notteboom, 2005; 2010; Feng \& Notteboom, 2013).

In line with the development and digital transformation of small and mediumsized ports, the term 'smart ports' is increasingly used in research papers 
and studies (Philipp, 2020), defined as a fully automated port connected via the internet of things (IoT) (Yang et al., 2018). Despite attempts to benchmark smart ports (Molavi et al., 2019; Philipp, 2020; Rodrigo González et al., 2020), no unified framework can be identified yet (Molavi et al., 2019).

Nevertheless, recent literature such as Heilig et al. (2017) and Ilin et al. (2019) examined the digital transformation of seaports and concluded that seaports have a high potential to improve productivity and efficiency in logistics by adopting key enabling technologies such as the internet of things, big data, ICT software and simulations, augmented reality or autonomous vehicles. However, the lack of awareness of small and medium-sized ports about tailor-made IT solutions or the existing opportunities to improve their infrastructure and supply chains still permeate through the industry (Philipp et al., 2018). Along these lines, Verina and Titko (2019) identified three main categories for a successful digital transformation: (i) technologies; (ii) process and management and (iii) people. Despite the positive effects on digital transformation, the capacity building of port employees/port community leads to the improvement or success of organisational processes (Saadat \& Saadat, 2016), supply chain integration (Zhu et al., 2018) and port performances (Meletiou, 2006).

This article focuses in particular on the category of people for a successful digital transformation mentioned above; thus, the theoretical concepts of knowledge base and absorptive learning (Cohen \& Levinthal, 1990) as well as collective learning (Bellini et al., 2020) are crucial for organisations to increase their ability to identify and integrate new digital trends into their business environment through existing human resources as well as to capitalise on the competitive market (see Asheim et al., 2017; Barzotto et al., 2019).

Cross-border approaches for knowledge acquisition are seen as effective learning opportunities capitalising on different skills, expertise and organisational cultures (Inkpen, 1998; Sweeney \& Evangelista, 2005). In addition, facilitating knowledge creation and positive learning influences the internalisation processes of organisations (Bathelt \& Li, 2020), underlining the development of small and medium-sized ports into transnational gateways (Feng \& Notteboom, 2013). Nevertheless, the efficiency of cross-border approaches in learning must meet three key criteria: learning intent, attractiveness of foreign learning source and the quality of relationship between the recipient and the source (Pérez-Nordtvedt et al., 2008). Additionally, cultural variations may influence the efficiency of cross-border knowledge transfer (Bhagat et al., 2002). Furthermore, Van 
Tatenhove (2015) emphasised the impact of marine governances for the particular field of maritime capacity building. Hence, different governance policies or frameworks can derail sufficient cross-border capacity building. Nevertheless, while the governance circumstances may differ between European seas-namely, the Baltic Sea, the Black Sea, the Mediterranean Sea and the North Sea-the settings are coherent within the region (Van Leeuwen et al., 2012), which underlines the geographical research scope of this article and the developed cross-border capacity-building frameworkthe Baltic Sea Region.

\section{Methodology}

The conducted research is based on inductive perspectives, using audited ports of the BSR as cases to analyse their needs for capacity building in the field of digital transformation. However, the article tries to gain insight into and explain a phenomenon on the European level with data gathered from a limited number of actors to develop and justify results applicable and transferable to actors in the whole BSR.

The conducted research is based on primary data gained from audits implemented with port representatives. The audit questionnaire was based on the digital readiness index for ports, developed by Philipp (2020). In total, 36 ports of the BSR were audited in line of face-to-face meetings or via an online form. The questionnaire consists of 38 questions, covering five different dimensions to evaluate the digital readiness of a port. For the implemented research, the authors used provided answers of the dimension 'Human Capital' only. However, the conducted research paper uses a mixed-methods approach with quantitative results of the audits to derive qualitative conclusions. Furthermore, desk research and case studies enlarged the scope of research activities.

Five methods were employed to explore the research objectives:

- Research approach: mixed methods, inductive

- Research tool: audits with 36 small and medium-sized ports of the BSR

- Research time scope: 10/2019-07/2020

- Research types: analytical, exploratory, qualitative, quantitative and practice-based

- Research methods: quantitative-data of implemented audits; qualitative—case studies, desk research 
Hence, the inductive research and its results are based on the constructivism and interpretivism of the researchers (see Mertens, 2010; Creswell, 2013, pp. 15-41). Both perspectives are used in the following chapters to identify the actually existing needs of small and medium-sized ports based on their audit inputs. In the process, the needs determine the proposed modules in the cross-border capacity-building framework, including their classification as compulsory or optional to foster digital transformation in small and medium-sized ports.

\section{Demand-side analysis of capacity building in ports}

In addition to the abovementioned research gap, port representatives participating in the mentioned audits that were carried out in line with the Connect2SmallPorts project emphasised a very low score (the average of 1.31 of 6) for the 'IT Knowledge and Skills' indicator, underlining the necessity to devise a new conceptual framework to increase the digital knowledge of the staff and port employees in small and medium-sized ports of the BSR. Paradoxically, the score for 'IT Training and Education Opportunities' was evaluated as quite high (the average of 3.97 of 6). This contrast suggests that the existing training models and opportunities provide educational content aside from the specific IT needs of small and medium-sized ports. To minimise this identified opposition, the present research paper introduces the cross-border conceptual framework of IT trainings for port employees/ community.

In search for a well justified and efficient concept, the researchers developed a demand analysis for capacity building based on the identified gaps in a port community. The structure was proposed by Gerlitz (2017), who used an evaluation system providing a scale of demand for thematic training modules. Based on the evaluation, the cross-border concept serves as congenial supply side. Table 1 illustrates the identified capacity-building demands, using the average score of the respective parameter within the yielded results from audits with 36 small and medium-sized ports in the BSR. As an evaluation, four stages showcase the magnitude of demand for the chosen parameters: 0 (none), + (marginal), ++ (average) and +++ (essential).

Based on the answers given by port representatives, several aspects could be excluded from the demand of capacity building for the port community. Firstly, the usage of 'Digital Communication Tools' for the external dissemination 
of port-related information is not a required content module for a training concept. Logically, the responsibility for external communication via online platforms and social media falls on a certain unit within the port ecosystem.

Secondly, four parameters were evaluated with a marginal demand to be integrated in the concept of cross-border capacity building: 'Usage of Drones', 'Localisation Technologies', 'IT and Data Security' and 'Operating Systems and Processes'. Despite the integration of drone systems as a key technology for the digital transformation of seaports (see Koroleva et al., 2019; Agatić \& Kolanović, 2020), only marginal demand could be identified in line with the audits. The reason behind that might be an overall low readiness for such high digital technologies in small and medium-sized ports (Philipp, 2020). An opposite argumentation can be provided for localisation technologies. This parameter's demand is also evaluated as marginal with the underlying reason that such technologies have already been used in seaports for a long time, decreasing the need of capacity building in this particular field (Steenken et al., 2004). The demand for operating systems and IT security is evaluated as being marginal as well. In the case of operating systems, port employees are often already educated in the ports themselves. For IT security, the authors do not comply with the yielded results and deduced marginal demand. Literature such as Jović et al. (2019) indicates increasing challenges and the importance of digital seaport security. Furthermore, Urciuoli et al. (2013) identified a gap in common security courses at the European level, which can be filled by the proposed cross-border concept.

Table 1. Evaluation of training demand parameter

\begin{tabular}{|l|l|}
\hline Parameter & Evaluation \\
\hline Innovation Cooperation & +++ \\
\hline Digital Business Models and Strategies & +++ \\
\hline Usage of Blockchain Technologies & +++ \\
\hline Big Data Analytics & ++ \\
\hline Autonomous Solutions & +++ \\
\hline Robotics and Artificial Intelligence & +++ \\
\hline Usage of Drones & + \\
\hline Localisation Technologies (GPS, RFID, etc.) & + \\
\hline IT and Data Security & + \\
\hline Internet of Things (IoT) & ++ \\
\hline Operating Systems and Processes & + \\
\hline Digital Communication Tools & 0 \\
\hline
\end{tabular}

Source: Authors' data 
Average demand in line with capacity building for port communities can be identified for the handling of big data and the internet of things. The use of both technologies is increasing in transport, logistics and maritime industry. In addition, they are already identified as key enabling technologies for the digital transformation of seaports (Sarabia-Jácome et al., 2019; Hopkins \& Hawking, 2018).

Essential demand can be identified within five parameters-'Innovation Cooperation', 'Digital Business Models and Strategies', 'Usage of Blockchain Technologies', 'Autonomous Solutions' and 'Artificial Intelligence and Robotics'. Those parameters will be adopted into training modules in line with the capacity-building framework. Innovation cooperation will be covered and supported by the cross-border approach of the concept. Artificial intelligence and robotics as well as autonomous solutions will be grouped under one module, since these are future technologies with an increasing demand in seaports (Ghaderi, 2017) but do not reflect the current challenges in small and medium-sized ports of the BSR.

In addition to the insights gained from the audits, a COVID-19 related module will be incorporated as well. De Rooij et al. (2020) indicated the main training needs of port communities in their business regarding the impact of the current pandemic situation and regulations. As a result, four topics with a high training demand were listed: routine vessel inspections, ill travellers, prevention measures as well as ill and exposed travellers. All four topics will be incorporated as one module to the cross-border capacitybuilding framework.

\section{The conceptual framework of cross-border capacity building}

As mentioned in the introduction, the maritime industry is facing new challenges, but these challenges, in turn, provide opportunities in the behaviour, interaction of port communities and access to new knowledge and improved educational offers. The developed cross-border training is intended as an online course to provide initial access for port representatives and support the cross-border character. Nevertheless, the framework can be adapted and implemented as a physical training schedule, but also in short term. 
Figure 1. Cross-border capacity-building structure

\begin{tabular}{|c|c|c|}
\hline \multirow[t]{3}{*}{$\begin{array}{l}\text { I. Compulsory } \\
\text { Modules }\end{array}$} & 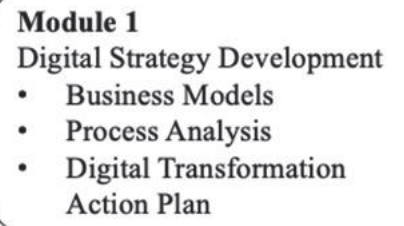 & $\begin{array}{l}\text { Module } 2 \\
\text { Blockchain Integration } \\
\text { - Feasibility Studies } \\
\text { - } \\
\text { - } \\
\text { - Sistributed-Ledger-Techn, Contracts } \\
\text { Value Chains }\end{array}$ \\
\hline & $\begin{array}{l}\text { Module } 3 \\
\text { IoT Integration } \\
\text { - } \quad \text { Feasibility Studies } \\
\text { - Implementation Fields } \\
\text { - } \quad \text { Big Data } \\
\text { - }\end{array}$ & $\begin{array}{l}\text { Module } 4 \\
\text { IT \& Data Security } \\
\text { - } \quad \text { Threats and Obstacles } \\
\text { - } \quad \text { Cyber Security } \\
\text { - } \quad \text { Surveillance }\end{array}$ \\
\hline & $\begin{array}{l}\text { Module 5 } \\
\text { COVID-19-Vessel inspection }\end{array}$ & ion measures, Traveller handling \\
\hline
\end{tabular}

\section{Regional Module}

\section{Module 6}

Analysis of regional knowledge competences and needs, expertise exchange, best practices, learning and collaborative studies to create synergies by cross-border knowledge cooperation

\section{Optional Modules}
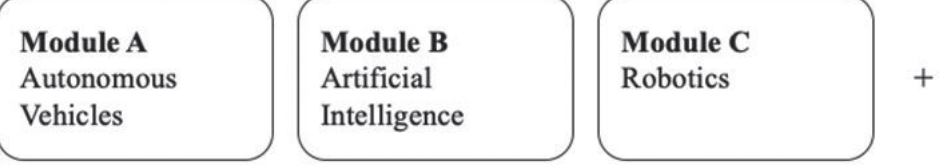

As to the demand-side analysis discussed in the previous chapter, the following argumentation will provide the corresponding capacity-building modules as the supply side. Basically, the framework can be divided into three parts: (i) compulsory modules, (ii) regional modules and (iii) optional modules. Compulsory modules are directly derived from the indicated demands (average and essential). Optional modules cover digitalised technologies, such as handling of autonomous vehicles which can be seen as pre-education since the small and medium-sized ports in the Baltic Sea area are currently on a lower digital level. Regional modules reflect the mentioned cross-border approach. The regions and countries face individual challenges but can also provide specific knowledge and competences in certain maritime fields. Therefore, an exchange between the regions is a key part of the framework for efficient learning from each other and sharing the best practices. This includes as a main requirement an exchange of 
regional maritime experts as lecturers or presenters in particular topics in line with the online sessions. In addition, an exchange of expertisephysical or online-offers high networking potential in the region for further collaboration in the industry. Figure 1 tries to illustrate this structure with all the three parts and presents the content covered in the proposed modules.

As mentioned, the compulsory modules are directly derived from the indicated needs and contain five main topics: Digital Strategy DevelopmentModule 1, Blockchain Integration-Module 2, IoT Integration-Module 3, IT $\&$ Data Security-Module 4 and COVID-19-Module 5. For each module, the main information of the topics requirements are covered by answering the questions what, why, where, when and how.

The regional module-Module 6-is to be planned, organised and implemented according to regional needs and competences as a mandatory part of the training schedule. Since the framework aims to provide a competence-building concept for the whole BSR, the heterogeneity of the seaport is considered. This includes their strengths as well as weaknesses in line with the digital transformation of small and medium-sized ports. To create synergy effects and foster competitiveness as well as innovation capacities for the region, the module is based on an exchange of expertise, such as knowledge, experiences, best practices and/or case studies.

Optional modules mainly cover technologies which require a high level of digital readiness and necessary infrastructures and can be enlarged by more modules than illustrated in Figure 1. As explained above, small and medium-sized ports are currently not in a position to integrate such technologies. Nevertheless, the modules can be integrated if necessary or a certain technology shall be implemented in the short-term perspective.

\section{Discussion}

The audits implemented in line with the European project Connect2SmallPorts indicated a very low digital capacity of human resources in small and mediumsized seaports of the BSR although opportunities for digital training were ranked high by port representatives. The presented concept tackled this gap in line with a missing collaboration and transregional view. The authors have addressed both the research gap and objectives by setting up a crossborder capacity-building framework for small and medium-sized ports as an 
adoptable and well-justified training structure for the digital transformation of port ecosystems.

Thus the research adds a new perspective to existing research in the maritime field by focusing on human capacity-building in applying digital technologies in the small and medium-sized ports of the BSR. This differs from previous researches related to digital transformation in the maritime sector due to their focus on technological requirements (see Acciaro et al., 2020; Voorspuij \& Becha, 2021).

While the capacity-building framework presented in this paper focuses on digital content only, it does not yet consider related policies, such as the environmental impact of small and medium-sized ports as training modules. Nevertheless, the current structure offers opportunities to add content-related modules. Thus, special research is needed to justify further involvement with regard to the needs and requirements of small and medium-sized ports.

In addition, the framework needs a clear elaboration on its transferability to other sea regions of the European Union. As Van Tatenhove (2015) has pointed out, different marine governances can influence the efficiency of maritime capacity building. Therefore, for transferring the framework to other regions, for example, the North Sea or the Black Sea, further analysis and elaboration on the modules has to be done.

Current limitations of the concept indicate a need to be aligned with the regional module. The regional module requires further analysis. While the first four modules may be standardised up to a certain level, the regional module can only be implemented in an efficient way as a tailor-made offer for the participants. Therefore, it is necessary not only to analyse the port demand but also regional challenges and opportunities to devise sufficient training content for this module.

Nevertheless, the proposed cross-border capacity-building framework can be implemented initially for port ecosystems to support the digital transformation of small and medium-sized ports for the BSR. The first steps have already been made within the Connect2SmallPorts project in developing and launching an online course portfolio, using the framework to set up the required modules. Also, it would be valuable to launch a testing phase to pilot the concept as physical training at small and medium-sized ports to gather insights and feedback for concept adjustment. 


\section{Conclusion}

The article aimed to develop a cross-border capacity-building framework for port communities with a focus on their digital transformation to overcome the challenges of small and medium-sized ports in the BSR and increase their competitiveness using the available human resources.

An analysis of training demands based on the results of the audits showed which particular fields need a higher focus to be covered in the training of port communities. Hence, individual topics were deemed justified to be implemented in compulsory modules in the training framework. In addition, the authors integrated modules for IT security as well as prevention measures in port operations due to the current COVID-19 pandemic.

Based on demand analysis, the framework was developed as tailormade supply side with three main parts: compulsory modules, a regional module and optional modules. The cross-border aspect of the framework is reflected in the regional module by supporting the creation of synergy effects in the BSR by expertise exchanges, for example, an exchange of knowledge, experiences, lecturers, as well as the best practices and case studies. Lastly, the digital technologies that require high digital readiness or certain infrastructure in the ports were added as optional modules to complete the cross-border capacity-building framework.

Christopher Meyer coordinates several European research projects at the European Project Center associated with the University of Wismar. After completing his master's degree in public economics, he started his studies as a PhD candidate at Tallinn University of Technology in Estonia, elaborating the impact of smart specialisation on the blue economy of the Baltic Sea area.

Laima Gerlitz is a researcher at Wismar University of Applied Sciences: Technology, Business and Design. She received her PhD focusing on the fields of project design and transport-related management at Tallinn University of Technology in 2018. Dr. Gerlitz's current research interests are: design and innovation, strategic design management, design management for enterprises, competitiveness and value creation deriving from design-driven approaches in organisational settings, particularly in the context of small manufacturing and high-tech enterprises and start-ups. 
Lawrence Henesey is an associated professor at Blekinge Institute of Technology, Sweden. His work focuses on the applications of technologies in distributed artificial intelligence for improved performances in logistics and transportation. Dr. Henesey has participated in various international, European Union and national research projects as principal investigator (PI), and has 29 years of industrial work experience, has been employed with various international companies all over Europe, the US and the Middle East. Dr. Henesey earned his $\mathrm{PhD}$ in computer science from Blekinge Institute of Technology.

\section{References}

Acciaro, M.; Renken, K. \& El Khadiri, N. (2020), 'Technological change and logistics development in European ports,' European Port Cities in Transition: Strategies for Sustainability, Cham: Springer, pp. 73-88.

https://doi.org/10.1007/978-3-030-36464-9_5

Agatić, A. \& Kolanović, I. (2020), 'Improving the seaport service quality by implementing digital technologies,' Scientific Journal of Maritime Research, vol. 34, pp. 93-101. https://doi.org/10.31217/p.34.1.11

Asheim, B.; Grillitsch, M. \& Trippl, M. (2017), 'Smart specialization as an innovation-driven strategy for economic diversification: examples from Scandinavian regions,' in Advances in the Theory and Practice of Smart Specialization, London \& Cambridge: Academic Press, pp. 73-97. https://doi.org/10.1016/B978-0-12-804137-6.00004-8

Barzotto, M.; Corradini, C.; Fai, F. M.; Labory, S. \& Tomlinson, P. R. (2019), 'Enhancing innovative capabilities in lagging regions: an extra-regional collaborative approach to RIS3,' Cambridge Journal of Regions, Economy and Society, vol. 12, no. 2, pp. 213-232. https://doi.org/10.1093/cjres/rsz003

Bathelt, H. \& Li, P. (2020), 'Processes of building cross-border knowledge pipelines,' Research Policy, vol. 49, no. 3, 103928.

https://doi.org/10.1016/j.respol.2020.103928

Bellini, N.; Lazzeri, G. \& Rovai, S. (2020), 'Patterns of policy learning in the RIS3 processes of less developed regions,' Regional Studies, vol. 55, no. 3, pp. 414-426. https://doi.org/10.1080/00343404.2020.1762855

Benassi, F.; Deva, M. \& Zindato, D. (2015), 'Graph regionalization with clustering and partitioning: an application for daily commuting flows in Albania,' Regional Statistics, vol. 5, no. 1, pp. 25-43. https://doi.org/10.2139/ssrn.2665523 
Bhagat, R. S.; Kedia, B. L.; Harveston, P. D. \& Triandis, H. (2002), 'Cultural variations in the cross-border transfer of organizational knowledge: an integrative framework,' Academy of Management Review, vol. 27, no. 2, pp. 204-221. https://doi.org/10.5465/amr.2002.6588000

BPO (2020), COVID-19's Impact on the Baltic Port \& Shipping Industry - SITRAP, Tallinn: Baltic Ports Organization \& Baltic Transport Journal.

Chen, Y.; Zhou, L.; Zhou, Y. \& Shen, R. (2017), 'Analysis on the core capacity building of different kinds of ports,' Chinese Journal of Frontier Health and Quarantine, no. 2.

Cohen, W. M. \& Levinthal, D. A. (1990), 'Absorptive capacity: A new perspective on learning and innovation,' Administrative Science Quarterly, vol. 31, no. 1, pp. 128-152. https://doi.org/10.2307/2393553

Communication from the Commission to the European Parliament, the European Council, the Council, the European Economic and Social Committee and the Committee of the Regions, The European Green Deal, COM/2019/640 final, 11.12.2019.

Creswell, J. W. (2013), Qualitative Inquiry and Research Design: Choosing among Five Approaches, 3rd ed., Los Angeles: SAGE Publications.

Czermański, E. (2017), 'Baltic shipping development in maritime spatial planning aspect,' Studia i Materiaty Instytutu Transportu i Handlu Morskiego, no. 14, pp. 48-64. https://doi.org/10.26881/sim.2017.4.03

De Rooij, D.; Belfroid, E.; Hadjichristodoulou, C.; Mouchtouri, V. A.; Raab, J. \& Timen, A. (2020), 'Assessing training needs in infectious disease management at major ports, airports and ground-crossings in Europe,' Research Square Preprint. https://doi.org/10.21203/rs.3.rs-33249/v1

Edler, J. \& Infante, V. (2019), 'Maritime and other key transport issues for the future - education and training in the context of lifelong learning,' Transactions on Maritime Science, vol. 8, no. 1, pp. 84-98.

https://doi.org/10.7225/toms.v08.n01.009

Efimova, E. G. \& Gapochka, A. A. (2020), 'Seaports as drivers of regional economic development: The case of Saint Petersburg and Leningrad Province,' Case Studies on Transport Policy, vol. 8, no. 2, pp. 383-393.

https://doi.org/10.1016/j.cstp.2019.10.003

European Commission (2014), List of Sea Ports in the Core and Comprehensive Networks. Retrieved from https://ec.europa.eu/transport/sites/transport/files/ modes/maritime/ports/doc/2014_list_of_329_ports_june.pdf [accessed Feb 2020]

European Commission (2017), Towards an Implementation Strategy for the Sustainable Blue Growth Agenda for the Baltic Sea Region, Luxembourg: Directorate-General for Maritime Affairs and Fisheries (European Commission), ECORYS, S.Pro. 
Feng, L. \& Notteboom, T. (2011), 'Small and medium-sized ports (SMPs) in multi-port gateway regions: the role of Yingkou port in the logistics systems of the Bohai Sea,' in T. Notteboom (ed.) Current Issues in Shipping, Ports and Logistics, Brussels: University Press Antwerp, pp. 543-563.

Feng, L. \& Notteboom, T. (2013), 'Peripheral challenge by small and medium sized ports (SMPs) in multi-port gateway regions: the case study of northeast of China,' Polish Maritime Research, Special Issue, vol. 20, pp. 55-66. https://doi.org/10.2478/pomr-2013-0027

Gerlitz, L. (2017), 'Design management as a domain of smart and sustainable enterprise: business modelling for innovation and smart growth in Industry 4.0,' Entrepreneurship and Sustainability Issues, vol. 3, no. 3, pp. 244-268. https://doi.org/10.9770/jesi.2016.3.3(3)

Ghaderi, H. (2017), 'Autonomous technologies in short sea shipping: trends, feasibility and implications,' Transport Reviews, vol. 39, no. 1, pp. 152-173. https://doi.org/10.1080/01441647.2018.1502834

Gianelle, C.; Kyriakou, D.; McCann, P. \& Morgan, K. (2020), 'Smart Specialisation on the move: reflections on six years of implementation and prospects for the future,' Regional Studies, vol. 54, no. 10, pp. 1323-1327.

https://doi.org/10.1080/00343404.2020.1817364

Heilig, L.; Lalla-Ruiz, E. \& Voß, S. (2017), 'Digital transformation in maritime ports: analysis and a game theoretic framework,' NETNOMICS: Economic Research and Electronic Networking, vol. 18, pp. 227-254. https://doi. org/10.1007/s11066-017-9122-x

Hopkins, J. \& Hawking, P. (2018), 'Big data analytics and IoT in logistics: a case study,' The International Journal of Logistics Management, vol. 29, no. 2, pp. 575-591. https://doi.org/10.1108/IJLM-05-2017-0109

Ilin, I.; Jahn, C.; Weigell, J. \& Kalyazina, S. (2019), 'Digital technology implementation for smart city and smart port cooperation,' in Atlantis Highlights in Computer Sciences: Proceedings of the International Conference on Digital Transformation in Logistics and Infrastructure, St. Petersburg, Russia, pp. 498-501. https://doi.org/10.2991/icdtli-19.2019.87

Inkpen, A. C. (1998), 'Learning and knowledge acquisition through international strategic alliances,' Academy of Management Perspectives, vol. 12, no. 4, pp. 69-80. https://doi.org/10.5465/ame.1998.1333953

Jović, M.; Tijan, E.; Aksentijević, S. \& Čišić, D. (2019), 'An overview of security challenges of seaport IoT systems,' in 42nd International Convention on Information and Communication Technology, Electronics and Microelectronics (MIPRO), 20-24 May 2019, Opatija, Croatia.

https://doi.org/10.23919/MIPRO.2019.8757206 
Koroleva, E.; Sokolov, S.; Makashina, I. \& Filatova, E. (2019), 'Information technologies as a way of port activity optimization in conditions of digital economy,' E3S Web of Conferences, vol. 138, 02002.

https://doi.org/10.1051/e3sconf/201913802002

Larosse, J.; Corpakis, D. \& Tuffs, R. (2020), The Green Deal and Smart Specialisation, Friends of Smart Specialisation, EFIS, Version 4, 20.2.2020.

Llano, C.; De la Mata, T.; Díaz-Lanchas, J. \& Gallego, N. (2017), 'Transportmode competition in intra-national trade: an empirical investigation for the Spanish case,' Transportation Research Part A: Policy and Practice, vol. 95, pp. 334-355. https://doi.org/10.1016/j.tra.2016.10.023

Meletiou, M. (2006), 'Improved port performance through training: the contribution of the International Labour Organization,' in Human Resources and Sea Ports Performance Proceedings of 22nd International Port Conference, Alexandria, Egypt.

Mertens, D. M. (2010), Research and Evaluation in Education and Psychology: Integrating Diversity with Quantitative, Qualitative, and Mixed Methods, 3rd ed., Thousand Oaks, CA: SAGE.

Molavi, A.; Lim, G. J. \& Race, B. (2020), 'A framework for building a smart port and smart port index,' International Journal of Sustainable Transportation, vol. 14, no. 9, pp. 686-700. https://doi.org/10.1080/15568318.2019.1610919

Notteboom, T. E. (2005), 'The peripheral port challenge in container port systems,' in H. Leggate, J. Mcconville \& A. Morvillo (eds.) International Maritime Transport Perspectives, New York: Routledge, pp. 173-188.

Notteboom, T. E. (2010), 'Concentration and the formation of multi-port gateway regions in the European container port system: an update,' Journal of Transport Geography, vol. 18, no. 4, pp. 567-583.

https://doi.org/10.1016/j.jtrangeo.2010.03.003

PAC2 (2014), A Cluster Initiative: Small and Medium Sized Ports as Hubs for Smart Growth and Sustainable Connectivity, 2 Seas Magazine - Special Focus, November 2014, ch. 1, pp. 6-15.

Pérez-Nordtvedt, L.; Kedia, B. L.; Datta, D. K. \& Rasheed, A. A. (2008), 'Effectiveness and efficiency of cross-border knowledge transfer: an empirical examination,' Journal of Management Studies, vol. 45, no. 4, pp. 714-744. https://doi.org/10.1111/j.1467-6486.2008.00767.x

Philipp, R. (2020), 'Digital readiness index assessment towards smart port development,' Sustainability Management Forum, vol. 28, pp. 49-60. https://doi.org/10.1007/s00550-020-00501-5

Philipp, R.; Gerlitz, L. \& Moldabekova, A. (2020), 'Small and medium-sized seaports on the digital track: tracing digitalisation across the South Baltic region by innovative auditing procedures,' Proceedings of International Conference on 
Reliability and Statistics in Transportation and Communication, pp. 351-362. https://doi.org/10.1007/978-3-030-44610-9_35

Philipp, R.; Gerlitz, L. \& Prause, G. (2018), 'Regional Häfen aufDigitalisierungskurs: Intelligentes Wachstum und nachhaltige Wertschöpfung entlang der kleinen und mittel-großen Häfen des Ostseeraumes,' in A. Cleve, E. Alde \& M. Wißotzki (eds.) Proceedings of WiWiTa 2018 Conference, Wismar, pp. 77-86.

Prause, G. (2014), 'Smart specialisation and EU Eastern Innovation Cooperation: a conceptual approach,' Baltic Journal of European Studies, vol. 4, no. 1(16), pp. 3-19. https://doi.org/10.2478/bjes-2014-0001

Rodrigo González, A.; González-Cancelas, N.; Molina Serrano, B. \& Orive, A. C. (2020), 'Preparation of a smart port indicator and calculation of a ranking for the Spanish port system,' Logistics, vol. 4, no. 2, p. 9.

https://doi.org/10.3390/logistics4020009

Saadat, V. \& Saadat, Z. (2016), 'Organizational learning as a key role of organizational success,' Procedia - Social and Behavioral Sciences, vol. 230, 3rd International Conference on New Challenges in management and Organization: Organization and Leadership, 2 May 2016, Dubai, UAE, pp. 219-225.

https://doi.org/10.1016/j.sbspro.2016.09.028

Sarabia-Jácome, D.; Lacalle, I.; Palau, C. E. \& Esteve, M. (2019), 'Enabling industrial data space architecture for seaport scenario,' in IEEE 5th World Forum on Internet of Things (WF-IoT), Limerick, Ireland, pp. 101-106. https://doi.org/10.1109/WF-IoT.2019.8767216

Steenken, D.; Voß, S. \& Stahlbock, R. (2004), 'Container terminal operation and operations research-a classification and literature review,' OR Spectrum, vol. 26, pp. 3-49. https://doi.org/10.1007/s00291-003-0157-z

Sweeney, E. \& Evangelista, P. (2005), 'Port community learning needs: analysis and design,' Pomorski zbornik, vol. 43, no. 1, pp. 27-43.

Thai, V.V. (2012), 'Competences required by port personnel in the new era: conceptual framework and case study,' International Journal of Shipping and Transport Logistics, vol. 4, no. 1, pp. 49-77. https://doi.org/10.1504/IJSTL.2012.044135

Urciuoli, L.; Ekwall, D. \& Torstensson, H. (2013), 'Achieving harmonized port security training in Europe-a critical review of EU legislative frameworks,' Journal of Transport and Security, vol. 6, pp. 357-375.

https://doi.org/10.1007/s12198-013-0123-1

Van Leeuwen, J.; Van Hoof, L. \& Van Tatenhove, J. (2012), 'Institutional ambiguity in implementing the European Union marine strategy framework directive,' Marine Policy, vol. 36, no. 3, pp. 636-643. https://doi.org/10.1016/j.marpol.2011.10.007

Van Tatenhove, J. P. (2015), 'Marine governance: institutional capacity-building in a multi-level governance setting,' in M. Gilek \& K. Kern (eds.) Governing Europe's 
Marine Environment: Europeanization of Regional Seas or Regionalization of EU Policies, Abingdon: Routledge, pp. 35-52.

Verina, N. \& Titko, J. (2019), 'Digital transformation: conceptual framework,' in Contemporary Issues in Business, Management and Economics Engineering 2019. International Scientific Conference, 9-10 May, Vilnius, Lithuania. https://doi.org/10.3846/cibmee.2019.073

Voorspuij, J. \& Becha, H. (2021), 'Digitalisation in maritime regional and global supply chains,' in M. Lind, M. Michaelides, R. Ward \& R. T. Watson (eds.) Maritime Informatics, Cham: Springer, pp. 65-80. https://doi.org/10.1007/978-3-030-50892-0_5

Yang, Y.; Zhong, M.; Yao, H.; Yu, F.; Fu, X. \& Postolache, O. (2018), 'Internet of Things for smart ports: technologies and challenges,' IEEE Instrumentation \& Measurement Magazine, vol. 21, no. 1, pp. 34-43. https://doi.org/10.1109/MIM.2018.8278808

Zhu, Q.; Krikke, H. \& Caniëls, M. C. J. (2018), 'Supply chain integration: value creation through managing inter-organizational learning,' International Journal of Operations \& Production Management, vol. 38, no. 1, pp. 211-229. https://doi.org/10.1108/IJOPM-06-2015-0372 